Research article

\title{
CYP17 5'-UTR MspA1 polymorphism and the risk of premenopausal breast cancer in a German population-based case-control study
}

\author{
Emaculate Verla-Tebit ${ }^{1}$, Shan Wang-Gohrke ${ }^{2}$ and Jenny Chang-Claude ${ }^{1}$
}

1Division of Clinical Epidemiology, German Cancer Research Center (Deutsches Krebsforschungszentrum), Heidelberg, Germany
2Molecular Biology Laboratory, Department of Obstetrics and Gynecology, University of Ulm, Ulm, Germany
Corresponding author: Shan Wang-Gohrke, shan.wang@medizin.uni-ulm.deJenny Chang-Claude, j.chang-claude@dkfz-heidelberg.de

Received: 13 Dec 2004 Revisions requested: 31 Jan 2005 Revisions received: 14 Feb 2005 Accepted: 18 Mar 2005 Published: 12 Apr 2005

Breast Cancer Research 2005, 7:R455-R464 (DOI 10.1186/bcr1027)

See related Commentary: http://breast-cancer-research.com/content/7/6/238

This article is online at: http://breast-cancer-research.com/content/7/4/R455

(c) 2005 Verla-Tebit et al.; licensee BioMed Central Ltd.

This is an Open Access article distributed under the terms of the Creative Commons Attribution License (http://creativecommons.org/licenses/by/ 2.0), which permits unrestricted use, distribution, and reproduction in any medium, provided the original work is properly cited.

\begin{abstract}
Introduction Studies on the association between the cytochrome P450c17 $\alpha$ gene (CYP17) 5'-untranslated region MspA1 genetic polymorphism and breast cancer risk have yielded inconsistent results. Higher levels of estrogen have been reported among young nulliparous women with the A2 allele. Therefore we assessed the impact of CYP17 genotypes on the risk of premenopausal breast cancer, with emphasis on parity.

Methods We used data from a population-based case-control study of women aged below 51 years conducted from 1992 to 1995 in Germany. Analyses were restricted to clearly premenopausal women with complete information on CYP17 and encompassed 527 case subjects and 904 controls, 99.5\% of whom were of European descent. The MspA1 polymorphism was analyzed using PCR-RFLP (PCR-restriction fragment length polymorphism) assay.
\end{abstract}

Results The frequencies of the variant allele among the cases and controls were $43 \%$ and $41 \%$, respectively. Overall, CYP17
A1/A2 and A2/A2 genotypes compared with the A1/A1 genotype were not associated with breast cancer, with adjusted odds ratios (ORs) of 1.04 and 1.23, respectively. Among nulliparous women, however, breast cancer risk was elevated for the $A 1 / A 2$ (OR $=1.31 ; 95 \%$ confidence interval $(\mathrm{Cl}) 0.74$ to 2.32) and the $A 2 / A 2$ genotype $(\mathrm{OR}=2.12 ; 95 \% \mathrm{Cl} 1.04$ to 4.32) compared with the $A 1 / A 1$ genotype, with a trend towards increasing risk associated with number of $\mathrm{A} 2$ alleles $(P=0.04)$. Otherwise, the CYP17 polymorphism was found neither to be an effect modifier of breast cancer risks nor to be associated with stage of disease.

Conclusion Our results do not indicate a major influence of CYP17 MspA1 polymorphism on the risk of premenopausal breast cancer, but suggest that it may have an impact on breast cancer risk among nulliparous women. The finding, however, needs to be confirmed in further studies.

\section{Introduction}

The risk of breast cancer is related to genetic, environmental, and lifestyle factors that influence the level of exposure to estrogens and other sex hormones [1]. Regarding genetic factors, high-penetrance cancer-susceptibility genes such as $B R C A 1$ and BRCA2 are associated with some cases of familial breast cancer, though this association accounts for only about $5 \%$ of all breast cancer cases [2], while low-penetrance genes together with endogenous and lifestyle factors are likely to account for a higher proportion of breast cancer cases [3].
These low-penetrance genes include genes involved in the metabolism of sex hormones. One such gene is CYP17, which codes for the enzyme cytochrome $\mathrm{P} 450 \mathrm{c} 17 \alpha$, responsible for catalyzing steroid $17 \alpha$-hydroxylase and 17,20 -lyase activities at key branch points in the estrogen biosynthesis pathway [4]. An increase or decrease in activity of these enzymes may alter the level of endogenous estrogen (estradiol), thereby influencing susceptibility to breast cancer $[5,6]$. One of the polymorphisms of the CYP17 gene is a thymidine substitution for cytosine ( $\mathrm{T}$ to $\mathrm{C}$ ) giving rise to an $M s p A 1$ restriction site at 
nucleotide 27 in the 5'-untranslated region (5'-UTR) promoter [7]. The MspA1 polymorphism has three genotypes: a homozygous wild type (A1/A1), a heterozygous variant (A1/ $\mathrm{A} 2$ ), and the homozygous variant (A2/A2) [6]. The T-to-C substitution was initially hypothesized to create an $\mathrm{Sp}-1$ binding site, which could lead to up-regulation of transcriptional activation of the variant allele and higher activity of the enzyme $[8,9]$, but this was not observed in experimental studies [10$12]$.

The A2 allele has been associated with higher levels of estrogen than the wild-type allele [13,14]. In premenopausal women, the A2 allele is also associated with higher levels of dehydroepiandrosterone sulfate, and in postmenopausal women, with higher levels of total estradiol [15]. Estrogen is a known risk factor for breast cancer and many reproductive factors that are associated with risk, such as nulliparity, late age at first pregnancy, early menarche, and late menopause, are considered markers of lifetime exposure to estrogens [1]. It has been hypothesized that the presence of the variant A2 allele could contribute to an increase in breast cancer risk by virtue of higher estrogen levels. Several epidemiological studies have investigated the association between the CYP17 MspA1 polymorphism and breast cancer risk, with inconsistent findings [16-19]. A systematic review of studies on CYP17 and breast cancer risk by Dunning and colleagues concluded that risk was not significantly altered by CYP17 genetic polymorphisms [5]. In addition, a meta-analysis of 15 case-control studies published between 1994 and 2001 showed that the CYP17 MspA1 polymorphism may be a weak modifier of breast cancer risk but is not a significant independent risk factor [6]. However, the meta-analysis failed to include one study which, if included, could suggest a possible small increase in risk of breast cancer associated with the A2 allele [20]. Ambrosone and colleagues [21] also found that CYP17 acts as an effect modifier of breast cancer risk, especially with factors that influence endogenous estrogen levels. Similar to findings of other studies, they reported a protective effect of late age at menarche $[8,13,22]$, and an increased risk with late age at first full-term pregnancy and use of oral contraceptives, among premenopausal women with the A1/A1 genotype.

It has been shown that premenopausal nulliparous women with the A2/A2 genotype have higher mean levels of serum estradiol than those with the A1/A1 genotype [14,23], implying that nulliparous women with the A2/A2 genotype may have a higher risk of breast cancer than nulliparous women with the A1/A1 genotype. Very few studies have looked at the risk of breast cancer associated with CYP17 in relation to parity $[22,24]$. This study therefore aimed to assess the risk of breast cancer and CYP17 genotype according to parity (nulliparous versus parous) and other risk factors for breast cancer among premenopausal women.

\section{Materials and methods}

\section{Study design and study population}

We used data from a population-based case-control study conducted from 1992 to 1995 in two regions of southern Germany (Freiburg and the Rhein-Neckar-Odenwald regions) [25]. The ethics committee of the University of Heidelberg reviewed the study protocol, and subjects who participated gave their informed consent. Subjects eligible for participation were German speaking, were under 51 years of age, resided within the study region, and had no previous history of breast cancer. Cases newly diagnosed with either in-situ or invasive breast cancer within the study period were identified through frequent monitoring of hospital admissions, surgery schedules, and pathology records from about 40 hospitals serving the study regions. There were also periodic checks of pathology institutions serving these hospitals, in order to identify any overlooked cases. There were 1,020 eligible case subjects, of whom 1,005 (98.5\%) were alive when identified. Of these living subjects, $706(70.2 \%)$ completed the study questionnaire and constituted the original population of case subjects, 152 $(15.1 \%)$ refused to participate, $85(8.5 \%)$ failed to respond, $51(5.1 \%)$ were not contacted because of the physician's refusal to allow contact, and $11(1.1 \%)$ were unable to participate because of health problems.

Controls were randomly selected from population registers of the study regions. An attempt was made to recruit two population controls per case, matched by age and study region. Subjects were not eligible as controls if they could not speak German, had moved out of the study region, had a previous history of primary breast cancer, were mentally handicapped, or had died. Of 2,257 eligible population controls, 1,381 $(61.2 \%)$ participated (these were considered the original control population), 658 (29.1\%) refused to participate, and 218 $(9.7 \%)$ did not respond.

All subjects were asked to complete a self-administered questionnaire on demographic factors, anthropometric measures, menstrual, reproductive, and breast feeding histories, use of contraceptives and exogenous hormones, medical and screening histories, first- and second-degree family history of breast cancer, occupational exposures, smoking history, and alcohol consumption. Information on exposure for cases and controls was truncated at a reference date, which was the date of diagnosis for cases and the date of completion of the questionnaire for controls. All subjects were asked to provide a blood sample, which was used for genotyping. The median time between diagnosis and interview for cases was 2 months.

The study population was homogeneous, with $95.1 \%$ being of German origin and $88.6 \%$ of the non-Germans being of European descent. A total of $99.5 \%$ of the sudy subjects (Germans and non-Germans) were of European descent. The mean age was 41.6 years ( \pm 5.8 standard deviations) for the cases and 41.7 years ( \pm 5.7 standard deviations) for the controls. 


\section{Genotyping}

Genomic DNA was extracted from the blood samples drawn into ethylenediaminetetraacetic acid tubes using Blood and Cell Culture DNA kits as described by the manufacturer (Qiagen GmbH, Hilden, Germany). The CYP17 5'-UTR MspAI polymorphism was analyzed using the previously described PCRRFLP assay [7]. Briefly, a PCR fragment containing the basepair change was amplified from genomic DNA by using primers (sense, 5'-CATTCGCACCTCTGGAGTC-3' ; antisense, 5'-GGCTCTTGGGGTACTTG-3'). After amplification, the PCR products were digested with the restriction endonuclease MspAl, subjected to electrophoresis through a $3 \%$ agarose gel, and visualized by staining the gel with ethidium bromide. Different genotypes could then be distinguished based on the size of the digested fragments.

\section{Statistical analysis}

We restricted our analysis to women clearly defined as premenopausal, since risk factors for breast cancer vary depending on menopausal status. Only women who still had menstrual cycles or reported natural amenorrhea for less than 6 months or more before the reference date (date of diagnosis for case subjects and date of completion of questionnaire for controls) were considered premenopausal. Women who reported natural amenorrhea 6 months before the reference date or bilateral oophorectomy were considered postmenopausal and hence not included in the analysis. Menopausal status for those who reported hysterectomy alone was classified as unknown and these subjects were also excluded, leaving $558(79.0 \%)$ cases and 1,116 (80.8\%) controls. Of these premenopausal subjects, 527 case subjects (94.4\%) and 904 controls (81.0\%) had complete information on CYP17 genotype, and therefore these 527 cases and 904 controls were included in the analysis.

The distribution of demographic characteristics and potential risk factors of breast cancer in this study population was compared with that of the original study population. Allele and genotype frequencies among cases and controls were calculated and deviation from Hardy-Weinberg equilibrium was examined using the $\chi^{2}$ test. The distributions of potential risk factors for breast cancer by CYP17 genotype in cases and controls were compared. Odds ratios (ORs) and 95\% confidence intervals $(95 \% \mathrm{Cls})$ were computed using multivariate conditional logistic regression analysis. Maximum-likelihood estimates were produced using the PHREG procedure in the SAS statistical software package (release 8.2; SAS Institute Inc, Cary, NC, USA). One-year age stratification was used to optimize age adjustment. Assessment of the association between CYP17 genotype and breast cancer was adjusted for potential confounders, including age at menarche, having ever used an oral contraceptive, total months of breastfeeding, family history of breast cancer in first-degree relatives, parity (defined as the number of full-term pregnancies resulting in either a live or a stillbirth), age at first full-term pregnancy (for parous women only), current body mass index, alcohol consumption, and level of education. Other variables such as study region, marital status, and smoking did not materially affect the risk estimates and were therefore not included in the model.

The effect of CYP17 genotype by parity (nulliparous and parous) and by other risk factors was examined to identify differential effects. We tested for trends in the logistic analyses by categorizing the exposure variables and treating the scored variables as continuous. All $P$ values computed in the analyses were two-tailed. We tested for multiplicative interaction by computing the cross product of the variables and including it in the model alongside its separate components. We also assessed the distribution of the CYP17 genotype with respect to stage of the disease (local: stages 1 and 2; advanced: stages 3 and 4) and investigated trends with the CochranArmitage test.

\section{Results}

There were no major differences in the distribution of demographic characteristics and potential risk factors of breast cancer between the original study population and this study population (Table 1). Subjects in this study were about a year younger than those in the originally selected population, because we included only premenopausal women, who are generally younger than the excluded postmenopausal women. The frequency of the variant allele (A2) in the study population was similar for the cases and the controls: $43 \%$ and $41 \%$, respectively. The genotype distribution was in agreement with that predicted under Hardy-Weinberg equilibrium, for both cases $(P=0.217)$ and controls $(P=0.380)$.

Table 2 shows the distribution of some risk factors for breast cancer among case subjects and controls by CYP17 genotype. $\chi^{2}$ tests for distribution revealed no significant differences among cases and controls in any of the genotype groups (A1/A1, A1/A2, A2/A2) with respect to age at menarche, age at first full-term pregnancy, parity, total months of breastfeeding, current body mass index, and educational level. Case subjects with the A1/A2 genotype were more likely than controls with this genotype to have used oral contraceptives. Compared with controls, case subjects with the A1/A1 genotype had significantly more family history of breast cancer and consumed more alcohol.

Overall, there was no significant association between the CYP17 genetic polymorphism and breast cancer risk (Table 3). The odds ratios for A1/A2 and A2/A2 genotypes were 1.04 and 1.23, respectively, in comparison with the A1/A1 genotype. Stratification by parity revealed a significantly increased risk in carriers of the A2/A2 genotype when compared with the A1/A1 genotype among nulliparous women $(O R=2.12)$. The risk associated with the A1/A2 genotype was elevated but did not reach statistical significance $(\mathrm{OR}=$ 
Breast Cancer Research Vol 7 No 4 Verla-Tebit et al.

Table 1

Comparison of demographic characteristics and potential risk factors for breast cancer in two study populations

\begin{tabular}{|c|c|c|c|c|}
\hline \multirow[t]{2}{*}{ Population statistics and characteristics } & \multicolumn{2}{|c|}{ Present study population } & \multicolumn{2}{|c|}{ Original study population ${ }^{\mathrm{a}}$} \\
\hline & Cases $(n=527)$ & Controls $(n=904)$ & Cases $(n=706)$ & Controls $(n=1,381)$ \\
\hline Mean age (years) at diagnosis or recruitment & 41.6 & 41.7 & 42.5 & 42.6 \\
\hline Mean BMI $\left(\mathrm{kg} / \mathrm{m}^{2}\right)$ & 24.0 & 23.9 & 24.1 & 24.2 \\
\hline Mean age (years) at menarche & 13.1 & 13.1 & 13.1 & 13.1 \\
\hline Mean age (years) at first full-term pregnancyb & 24.4 & 24.9 & 24.2 & 24.3 \\
\hline \multicolumn{5}{|l|}{ Population characteristics (\%) } \\
\hline \multicolumn{5}{|l|}{ Study region } \\
\hline Rhein-Neckar-Odenwald & 71.7 & 70.7 & 70.0 & 69.3 \\
\hline Freiburg & 28.3 & 29.3 & 30.0 & 30.7 \\
\hline \multicolumn{5}{|l|}{ Marital status ${ }^{c}$} \\
\hline Single & 9.3 & 9.8 & 7.8 & 8.4 \\
\hline Married/with partner & 81.0 & 80.0 & 81.2 & 78.3 \\
\hline Widowed, divorced or separated & 9.7 & 10.2 & 10.9 & 13.2 \\
\hline \multicolumn{5}{|l|}{ Nationality } \\
\hline German & 91.8 & 97.0 & 91.2 & 95.8 \\
\hline Non-German & 8.2 & 3.0 & 8.8 & 4.2 \\
\hline \multicolumn{5}{|l|}{ Educational level } \\
\hline Low & 13.5 & 11.7 & 14.7 & 14.2 \\
\hline Intermediate & 63.7 & 60.7 & 63.3 & 60.3 \\
\hline High & 22.8 & 27.6 & 22.0 & 25.5 \\
\hline \multicolumn{5}{|l|}{ Parity } \\
\hline 0 & 23.5 & 22.0 & 21.7 & 20.8 \\
\hline 1 & 27.7 & 24.1 & 29.0 & 24.5 \\
\hline 2 & 39.5 & 37.5 & 38.5 & 38.0 \\
\hline $3+$ & 9.3 & 16.4 & 10.8 & 16.7 \\
\hline \multicolumn{5}{|l|}{ Oral contraceptive use ${ }^{d}$} \\
\hline No & 16.1 & 19.7 & 18.1 & 19.8 \\
\hline Yes & 83.9 & 80.1 & 81.9 & 80.0 \\
\hline \multicolumn{5}{|l|}{ Breastfeeding ${ }^{b}$} \\
\hline Never & 28.8 & 26.5 & 31.3 & 29.2 \\
\hline Ever & 71.2 & 73.5 & 68.7 & 70.8 \\
\hline \multicolumn{5}{|l|}{ First-degree family history of breast cancer } \\
\hline No & 87.7 & 94.7 & 87.7 & 94.9 \\
\hline Yes & 12.3 & 5.3 & 12.3 & 5.1 \\
\hline \multicolumn{5}{|l|}{ Daily average alcohol intake } \\
\hline $0 \mathrm{~g}$ & 20.7 & 16.4 & 21.7 & 17.3 \\
\hline $1-18 \mathrm{~g}$ & 65.6 & 74.5 & 63.8 & 74.1 \\
\hline$>18 \mathrm{~g}$ & 13.7 & 9.1 & 14.5 & 8.7 \\
\hline
\end{tabular}

aAll who completed questionnaires. bLimited to parous women. cTwo controls from the original study population had unknown marital status. dThree controls from the original study and two controls from the present study have missing data. BMl, body mass index. 
Table 2

Distribution of breast cancer risk factors according to CYP17 genotype for premenopausal women in Germany

\begin{tabular}{|c|c|c|c|c|c|c|}
\hline \multirow[t]{3}{*}{ Patient characteristics } & \multicolumn{6}{|c|}{ CYP17 genotype } \\
\hline & \multicolumn{2}{|c|}{$\mathrm{A} 1 / \mathrm{A} 1(n=503)$} & \multicolumn{2}{|c|}{$\mathrm{A} 1 / \mathrm{A} 2(n=668)$} & \multicolumn{2}{|c|}{ A2/A2 $(n=260)$} \\
\hline & Cases, no. (\%) & Controls no. (\%) & Cases, no. (\%) & Controls no. (\%) & Cases, no. (\%) & Controls no. (\%) \\
\hline \multicolumn{7}{|c|}{ Age at menarche (years) ${ }^{a}$} \\
\hline$<13$ & $68(37.8)$ & $123(38.2)$ & $84(34.4)$ & $149(35.1)$ & $34(33.0)$ & $51(32.5)$ \\
\hline$\geq 13$ & $112(62.2)$ & $199(61.6)$ & $158(64.8)$ & $275(64.9)$ & $68(66.0)$ & $106(67.5)$ \\
\hline \multicolumn{7}{|c|}{ Age at first full-term pregnancy (years) ${ }^{\mathrm{b}}$} \\
\hline$<25$ & $69(49.6)$ & $125(49.4)$ & $106(56.1)$ & $172(52.1)$ & $40(53.3)$ & $55(45.1)$ \\
\hline$\geq 25$ & $70(50.4))$ & $128(50.6)$ & $83(43.9)$ & $158(47.9)$ & $35(46.7)$ & 67 (54.9) \\
\hline \multicolumn{7}{|l|}{ Parity } \\
\hline 0 birth & $41(22.8)$ & $70(21.7)$ & $55(22.5)$ & $94(22.2)$ & $28(27.2)$ & 35 (22.3) \\
\hline $1-2$ births & $123(68.3)$ & $201(62.2)$ & $168(68.9)$ & $260(61.3)$ & $63(61.2)$ & $96(61.1)$ \\
\hline$>2$ births & $16(8.9)$ & $52(16.1)$ & $21(8.6)$ & $70(16.5)$ & $12(11.6)$ & $26(16.6)$ \\
\hline \multicolumn{7}{|c|}{ Total months of breastfeeding } \\
\hline 0 & $43(30.9)$ & $65(25.7)$ & $53(28.0)$ & $94(28.5)$ & $20(26.7)$ & $28(22.9)$ \\
\hline $1-12$ & $86(61.9)$ & $156(61.7)$ & $117(61.9)$ & $186(56.4)$ & $50(66.8)$ & $74(60.7)$ \\
\hline$>12$ & $10(7.2)$ & $32(12.6)$ & $19(10.1)$ & $50(15.2)$ & $5(6.7)$ & $20(16.4)$ \\
\hline \multicolumn{7}{|c|}{ Ever use oral contraceptive ${ }^{c}$} \\
\hline No & $30(17.1)$ & $62(19.4)$ & $31(13.0)$ & $84(20.0)^{*}$ & 24 (23.3) & $32(20.5)$ \\
\hline Yes & $146(82.9)$ & $258(80.6)$ & $207(87.0)$ & $336(80.0)$ & $79(76.7)$ & $124(79.5)$ \\
\hline \multicolumn{7}{|c|}{ Family history of breast cancer in first-degree relative } \\
\hline No & $150(83.3)$ & $306(94.7)^{*}$ & $217(88.9)$ & $407(96.0)$ & $95(92.2)$ & $143(91.1)$ \\
\hline Yes & $30(16.7)$ & $17(5.3)$ & $27(11.1)$ & $17(4.0)$ & $8(7.8)$ & $14(8.9)$ \\
\hline \multicolumn{7}{|l|}{ Current BMI $(\mathrm{k} / \mathrm{m} 2)^{\mathrm{d}}$} \\
\hline$<20.0$ & $26(14.4)$ & $35(10.8)$ & $39(16.0)$ & $47(11.1)$ & $10(9.7)$ & $25(15.9)$ \\
\hline $20.0-25.0$ & $95(52.8)$ & $191(59.1)$ & $130(53.3)$ & $245(57.8)$ & $64(62.1))$ & $87(55.4)$ \\
\hline $25.1-30.0$ & $38(21.1)$ & $71(22.0)$ & $51(20.9)$ & $95(22.4)$ & $20(19.4)$ & $30(19.1)$ \\
\hline$>30.0$ & $20(11.1)$ & $25(7.7)$ & $24(9.8)$ & $37(8.7)$ & $9(8.7)$ & $15(9.6)$ \\
\hline \multicolumn{7}{|l|}{ Educational level } \\
\hline Low & $24(13.4)$ & $39(12.1)$ & $31(12.7)$ & $50(11.8)$ & $16(15.5)$ & $17(10.8)$ \\
\hline Middle & $114(63.3)$ & $200(61.9)$ & $159(65.2)$ & $262(61.8)$ & $63(61.2)$ & $87(55.4)$ \\
\hline High & $42(23.3)$ & $84(26.0)$ & $54(22.1)$ & $112(26.4)$ & 24 (23.3) & $53(33.8)$ \\
\hline \multicolumn{7}{|c|}{ Alcohol consumption (g/day) } \\
\hline 0 & $39(21.7)$ & $52(16.1)^{*}$ & $52(21.3)$ & $72(17.0)$ & $18(17.5)$ & 24 (15.3) \\
\hline $1-18$ & $118(65.5)$ & $246(76.2)$ & $158(64.8)$ & $309(72.9)$ & $70(68.0)$ & $119(75.8)$ \\
\hline$>18$ & $23(12.8)$ & $25(7.7)$ & 34 (13.9) & $43(10.1)$ & $15(14.5)$ & $14(8.8)$ \\
\hline
\end{tabular}

aData were missing for one control with A1/A1 genotype, two cases with A1/A2 genotype, and one case with A2/A2 genotype. bLimited to parous women. 'Data were missing for four cases and three controls with A1/A1 genotype; six cases and four controls with A1/A2 genotype, and one control with A2/A2 genotype. dData were missing for one case and one control with A1/A1 genotype. * $\chi^{2}$ test, $P<0.05$. BMl, body mass index. 
Table 3

Association between CYP17 genetic polymorphisms and premenopausal breast cancer risk by parity in Germany

\begin{tabular}{|c|c|c|c|c|}
\hline CYP17 genotype & Cases, no. $(\%)(n=527)$ & Controls, no. $(\%)(n=904)$ & Age-adjusted OR (95\% Cl)a & Multivariate-adjused OR $(95 \% \mathrm{Cl})^{\mathrm{b}}$ \\
\hline \multicolumn{5}{|l|}{ All subjects ${ }^{c}$} \\
\hline $\mathrm{A} 1 / \mathrm{A} 1$ & $180(34.2)$ & $323(35.7)$ & 1.00 & 1.00 \\
\hline $\mathrm{A} 1 / \mathrm{A} 2$ & $244(46.2)$ & $424(46.9)$ & $1.02(0.80-1.31)$ & $1.04(0.81-1.34)$ \\
\hline $\mathrm{A} 2 / \mathrm{A} 2$ & $103(19.6)$ & $157(17.4)$ & $1.18(0.87-1.61)$ & $1.23(0.89-1.69)$ \\
\hline Trend test $P$ & & & 0.34 & 0.24 \\
\hline \multicolumn{5}{|l|}{ Parous women ${ }^{d}$} \\
\hline $\mathrm{A} 1 / \mathrm{A} 1$ & $139(34.5)$ & $253(35.9)$ & 1.00 & 1.00 \\
\hline $\mathrm{A} 1 / \mathrm{A} 2$ & $189(46.9)$ & $330(46.8)$ & $1.02(0.78-1.35)$ & $1.04(0.78-1.37)$ \\
\hline $\mathrm{A} 2 / \mathrm{A} 2$ & $75(18.6)$ & $122(17.3)$ & $1.13(0.79-1.61)$ & $1.14(0.79-1.65)$ \\
\hline Trend test $P$ & & & 0.54 & 0.50 \\
\hline \multicolumn{5}{|l|}{ Nulliparous women } \\
\hline $\mathrm{A} 1 / \mathrm{A} 1$ & $41(33.0)$ & $70(35.2)$ & 1.00 & 1.00 \\
\hline $\mathrm{A} 1 / \mathrm{A} 2$ & $55(44.4)$ & $94(47.2)$ & $1.23(0.72-2.07)$ & $1.31(0.74-2.32)$ \\
\hline $\mathrm{A} 2 / \mathrm{A} 2$ & $28(22.6)$ & $35(17.6)$ & $1.74(0.90-3.38)$ & $2.12(1.04-4.32)$ \\
\hline Trend test $P$ & & & 0.11 & 0.04 \\
\hline
\end{tabular}

Table 4

Joint effects of CYP17 polymorphisms and parity on risk of premenopausal breast cancer in Germany

\begin{tabular}{|c|c|c|c|c|}
\hline CYP17 genotype & Cases, no. (\%) & Controls, no. (\%) & OR $(95 \% \mathrm{Cl})^{\mathrm{a}}$ & OR $(95 \% \mathrm{Cl})^{\mathrm{b}}$ \\
\hline \multicolumn{5}{|l|}{ Parous women } \\
\hline $\mathrm{A} 1 / \mathrm{A} 1$ & $139(26.4)$ & $253(28.0)$ & 1.00 & 1.00 \\
\hline $\mathrm{A} 1 / \mathrm{A} 2$ & $189(35.9)$ & $330(36.5)$ & $1.03(0.78-1.36)$ & $1.05(0.79-1.39)$ \\
\hline $\mathrm{A} 2 / \mathrm{A} 2$ & $75(14.2)$ & $122(13.5)$ & $1.12(0.79-1.60)$ & $1.16(0.80-1.66)$ \\
\hline \multicolumn{5}{|l|}{ Nulliparous women } \\
\hline $\mathrm{A} 1 / \mathrm{A} 1$ & $41(7.8)$ & $70(7.7)$ & $1.04(0.67-1.61)$ & $1.01(0.62-1.67)$ \\
\hline $\mathrm{A} 1 / \mathrm{A} 2$ & $55(10.4)$ & $94(10.4)$ & $1.04(0.70-1.56)$ & $1.05(0.66-1.67)$ \\
\hline $\mathrm{A} 2 / \mathrm{A} 2$ & $28(5.3)$ & $35(3.9)$ & $1.43(0.83-2.46)$ & $1.48(0.82-2.70)$ \\
\hline
\end{tabular}

aAge-adjusted odds ratio (OR) and 95\% confidence interval (Cl). bMultivariate adjusted OR and 95\% Cl. Adjusted for age at menarche in years ( $\leq$ $12,13$ to $14,15+)$; oral contraceptive use (no, yes); total months of breastfeeding $(0,1$ to $12,>12)$; alcohol consumption $(0,1$ to $18,>18 \mathrm{~g} /$ day); current body mass index as continuous variable; educational level (low, middle, high).

1.31). There was a trend towards increasing risk with the number of variant alleles carried, which was statistically significant among nulliparous women $(P=0.04)$ but nonsignificant among parous women ( $P$ for interaction $=0.87$ ) (Table 3$)$. Table 4 shows the joint effects of CYP17 genotypes and parity. In comparison with parous women with the A1/A1 genotype, the greatest risk increase was seen for nulliparous women with the A2/A2 genotype (OR $=1.48)$.
In Table 5, we show results regarding some potential risk factors of breast cancer by CYP17 genotype, both overall and with further stratification by parity. Because of limited power for subgroup analyses, we combined A1/A2 and A2/A2 genotypes, as both groups are considered putative high-risk groups. Late age at menarche was not associated with breast cancer risk, irrespective of genotype and parity. The odds ratio for nulliparous women with the A1/A1 genotype who had ever used oral contraceptives was elevated compared with those 
Table 5

Association between some potential risk factors of breast cancer by CYP17 genotype among premenopausal women in Germany

\begin{tabular}{|c|c|c|c|c|c|c|c|c|c|}
\hline \multirow[t]{2}{*}{ Factor } & \multicolumn{3}{|c|}{ All data } & \multicolumn{3}{|c|}{$\mathrm{A} 1 / \mathrm{A} 1$} & \multicolumn{3}{|c|}{$A 1 / A 2$ and $A 2 / A 2$} \\
\hline & $\begin{array}{c}\text { Cases }(n= \\
527)\end{array}$ & $\begin{array}{c}\text { Controls }(n= \\
904)\end{array}$ & $\begin{array}{l}\mathrm{OR}^{\mathrm{a}}(95 \% \\
\quad \mathrm{Cl})\end{array}$ & $\begin{array}{c}\text { Cases }(n= \\
180)\end{array}$ & $\begin{array}{c}\text { Controls }(n= \\
323)\end{array}$ & $\mathrm{OR}^{\mathrm{a}}(95 \% \mathrm{Cl})$ & $\begin{array}{c}\text { Cases }(n= \\
347)\end{array}$ & $\begin{array}{c}\text { Controls }(n= \\
581)\end{array}$ & $\begin{array}{l}\mathrm{OR}^{\mathrm{a}}(95 \% \\
\quad \mathrm{Cl})\end{array}$ \\
\hline \multicolumn{10}{|c|}{ Age at menarche ${ }^{b}$} \\
\hline$<13$ years & 186 & 323 & 1.00 & 68 & 123 & 1.00 & 118 & 200 & 1.00 \\
\hline$\geq 13$ years & 338 & 580 & $\begin{array}{c}1.00(0.80- \\
1.27)\end{array}$ & 112 & 199 & $\begin{array}{c}1.01(0.67- \\
1.51)\end{array}$ & 226 & 381 & $\begin{array}{c}1.00(0.75- \\
1.34)\end{array}$ \\
\hline \multicolumn{10}{|c|}{ Age at menarche, nulliparous women } \\
\hline$<13$ years & 43 & 64 & 1.00 & 17 & 24 & 1.00 & 26 & 40 & 1.00 \\
\hline$\geq 13$ years & 79 & 135 & $\begin{array}{c}0.79(0.48- \\
1.31)\end{array}$ & 24 & 46 & $\begin{array}{c}0.98(0.38- \\
2.55)\end{array}$ & 55 & 89 & $\begin{array}{c}0.91(0.47- \\
1.78)\end{array}$ \\
\hline \multicolumn{10}{|c|}{ Age at menarche, parous women } \\
\hline$<13$ years & 143 & 259 & 1.00 & 51 & 99 & 1.00 & 92 & 160 & 1.00 \\
\hline$\geq 13$ years & 259 & 445 & $\begin{array}{c}1.11(0.85- \\
1.45)\end{array}$ & 88 & 153 & $\begin{array}{c}1.08(0.68- \\
1.72)\end{array}$ & 171 & 292 & $\begin{array}{c}1.09(0.78- \\
1.53)\end{array}$ \\
\hline \multicolumn{10}{|l|}{ Pill use ${ }^{c}$} \\
\hline Never & 85 & 178 & 1.00 & 30 & 62 & 1.00 & 55 & 116 & 1.00 \\
\hline Ever & 442 & 724 & $\begin{array}{c}1.23(0.91- \\
1.66)\end{array}$ & 150 & 260 & $\begin{array}{c}1.22(0.72- \\
2.09)\end{array}$ & 292 & 464 & $\begin{array}{c}1.24(0.86- \\
1.79)\end{array}$ \\
\hline \multicolumn{10}{|c|}{ Pill use, nulliparous women } \\
\hline Never & 25 & 48 & 1.00 & 10 & 23 & 1.00 & 15 & 25 & 1.00 \\
\hline Ever & 99 & 150 & $\begin{array}{c}1.64(0.87- \\
3.08)\end{array}$ & 31 & 46 & $\begin{array}{c}2.60(0.81- \\
8.43)\end{array}$ & 68 & 104 & $\begin{array}{c}1.35(0.59- \\
3.10)\end{array}$ \\
\hline \multicolumn{10}{|c|}{ Pill use, parous women } \\
\hline Never & 60 & 130 & 1.00 & 20 & 39 & 1.00 & 40 & 91 & 1.00 \\
\hline Ever & 343 & 574 & $\begin{array}{c}1.26(0.89- \\
1.80)\end{array}$ & 119 & 214 & $\begin{array}{c}1.10(0.58- \\
2.09)\end{array}$ & 224 & 360 & $\begin{array}{c}1.35(0.88- \\
2.05)\end{array}$ \\
\hline \multicolumn{10}{|c|}{ Age at first full-term preganancyd } \\
\hline$<25$ years & 215 & 352 & 1.00 & 69 & 125 & 1.00 & 146 & 227 & 1.00 \\
\hline$\geq 25$ years & 188 & 353 & $\begin{array}{c}0.86(0.66- \\
1.14)\end{array}$ & 70 & 128 & $\begin{array}{c}0.98(0.60- \\
1.59)\end{array}$ & 118 & 225 & $\begin{array}{c}0.79(0.56- \\
1.11)\end{array}$ \\
\hline \multicolumn{10}{|c|}{ Breastfeeding status $^{d}$} \\
\hline Never & 116 & 187 & 1.00 & 43 & 65 & 1.00 & 73 & 122 & 1.00 \\
\hline Ever & 287 & 518 & $\begin{array}{c}0.90(0.68- \\
1.20)\end{array}$ & 96 & 188 & $\begin{array}{c}0.70(0.43- \\
1.16)\end{array}$ & 191 & 330 & $\begin{array}{c}1.02(0.71- \\
1.46)\end{array}$ \\
\hline \multicolumn{10}{|c|}{ Total months of breastfeeding among parous ever breastfed women } \\
\hline $1-12$ & 253 & 416 & 1.00 & 86 & 156 & 1.00 & 167 & 260 & 1.00 \\
\hline$>12$ & 34 & 102 & $\begin{array}{c}0.56(0.36- \\
0.87)\end{array}$ & 10 & 32 & $\begin{array}{c}0.69(0.30- \\
1.60)\end{array}$ & 24 & 70 & $\begin{array}{c}0.53(0.31- \\
0.90)\end{array}$ \\
\hline
\end{tabular}

aMultivariate adjusted odds ratio (OR) and 95\% confidence interval (Cl). Adjusted for alcohol consumption (0, 1 to 18 , >18 g/day); current body mass index as continuous variable; educational level (low, middle, high); family history of breast cancer in first-degree relative (no, yes); parity ( 0 , 1 to 2 births, $3+$ births), and other variables in the table where appropriate. bThree cases and one control had missing data. cTwo controls had missing data. dLimited to parous women.

who had never used oral contraceptives (OR $=2.60)$. The effect of breastfeeding among parous women (those who had ever breastfed versus those who had never breastfed) did not differ by genotype. However, among the parous women who had ever breastfed, breastfeeding for more than 12 months was associated with a risk reduction $(O R=0.56)$ when com- pared with 1 to 12 months of breastfeeding (Table 5). This effect did not differ according to CYP17 genotype ( $P$ for interaction $=0.48$ ). Age at first full-term pregnancy was not associated with breast cancer risk in this study and the result was not altered when genotype status was taken into consideration. 
We did not find any evidence of an association between CYP17 genotype and stage of breast cancer, with $65.5 \%$ of those with local disease and $68.1 \%$ of those with the advanced disease, respectively, being carriers of the A2 allele.

\section{Discussion}

The impact of CYP17 genetic polymorphism on the risk of breast cancer gained a lot of interest after Feigelson and colleagues first reported an increase in risk of advanced breast cancer for carriers of the A2 allele [8]. With a few exceptions $[19,26]$, most subsequent studies did not find an overall increase in risk with the A2/A2 genotype [17,21,22,24,2731]. The $A 2$ allele has been shown to be associated with higher levels of estrogen in two studies [13,14], although a recent study did not observe higher levels of estrogen with the A2 allele [32]. Hong and colleagues recently reported that in premenopausal women, the A2 allele is associated with higher levels of dehydroepiandrosterone sulfate, which is a precursor to estrogens and androgens [15]. Despite the higher levels of this precursor in these subjects, there was no corresponding elevation of estradiol levels, which could be due partly to the difficulty of assessing representative estrogen levels based on a single measure $[15,33]$.

We did not observe an overall increase in risk associated with the A2/A2 genotype compared with the A1/A1 genotype. However, we found an increased risk associated with the $A 2 /$ A2 compared with the A1/A1 genotype among nulliparous women. This observation supports findings from a previous study indicating that nulliparous women with the A2/A2 genotype have higher mean levels of serum estradiol than those with the A1/A1 genotype [14]. Jernström and colleagues [34] also found out that the urinary ratio of the less potent 2-hydroxyestrone to the more potent $16 \alpha$-hydroxyestrone is lower among nulliparous women with the A2/A2 genotype compared with the $A 1 / A 1$ genotype. A low urinary ratio of 2 hydroxyestrone to $16 \alpha$-hydroxyestrone has been reported to be associated with increased risk of breast cancer in premenopausal women [35]. This could explain our finding of increased risk of nulliparous premenopausal women with the A2/A2 genotype. Despite the biologically plausible mechanisms, this result should be interpreted with caution, because the numbers of subjects were small in this group and we did not observe any significant gene-parity effect modification. An increased risk has also been reported for nulliparous women and women who had had their first full-term pregnancy after the age of 30 years for carriers of at least one A2 allele among Chinese women in Singapore, though this was more pronounced in the postmenopausal group with that allele [24]. In the same line, a lower risk was observed for parous women with the A1/A1 genotype compared with nulliparous women with the same genotype [22]. Altogether, these findings suggest that the increased risk associated with $A 2$ alleles may be more easily observable in nulliparous women because the greater lifetime exposure to circulating steroid hormones associated with this genotype is not altered by reproductive events.

We found no evidence of the previously reported effect modification for later age at menarche by the A1/A1 genotype $[8,13,21,22]$. We also did not find any association with respect to age at first full-term pregnancy. These associations were still absent after stratification by parity. A number of studies have also not been able to detect an association $[17,29,30]$, including one of the largest case-control studies on this topic [31]. We observed an increased risk for oral contraceptive use compared with those who had never used oral contraceptives among nulliparous women with the A1/A1 genotype, although this might be a chance finding, especially as the number of subjects in this subgroup was small. Selection bias could also explain the findings if nulliparous case subjects with the A1/A1 genotype who participated in the study are more likely to use oral contraceptives. This is unlikely, however, as subjects are aware neither of their own genetype nor of the risk associated with it. Ambrosone and colleagues reported similar findings, though this was for all premenopausal women and not only in the nulliparous group [21]. They argued that oral contraceptive use might affect risk only in an environment of lower estrogens, seen in carriers of the A1/A1 genotype. Among parous women who had ever breastfed, we found a risk reduction for greater than 12 months of breastfeeding compared with 1 to 12 months of breastfeeding, but this effect did not differ with CYP17 genotype.

We also assessed the impact of CYP17 on stage of breast cancer, and, as in other studies [22,30,31], we were not able to confirm the increased risk for advanced breast cancer reported previously $[8,26]$. The association with stage was found in studies that included subjects having different racial and ethnic backgrounds. However, a possible bias due to population stratification can be excluded, as this effect was observed across all the ethnic groups [26].

We found fewer A2/A2 carriers in cases with a positive family history of breast cancer in first-degree relatives than in all controls, irrespective of family history of breast cancer (12.3\% versus $17.4 \% ; P=0.21$ ). This contradicts the findings of Spurdle and colleagues [27], who observed more of the A2/A2 genotype among cases with a positive family history of breast cancer in first- or second-degree relatives than in all controls. Their study subjects were below the age of 40 , whereas most of our study subjects (70\%) were aged 40 or above. In addition, they reported a deviation from Hardy-Weinberg equilibrium among cases with a positive family history of breast cancer, whereas we did not observe a deviation in this group $\left(\chi^{2}=0.25 ; P=\right.$ $0.62)$. Jernström and colleagues in their study on nulliparous young women also reported that carriers of the A2/A2 genotype had less family history of breast cancer in first- or seconddegree relatives than carriers of the $A 1 / A 2$ and $A 1 / A 1$ genotypes combined [34]. 


\section{Conclusion}

Our results do not suggest a major influence of CYP17 genetic polymorphism on the risk of premenopausal breast cancer generally, but they do suggest an increase in risk for nulliparous women with the A2/A2 genotype. The resolution of the question regarding the role of the CYP17 genotype in breast cancer risk may require a better understanding of the functional variants discussed. A more comprehensive haplotype analysis would help to clarify whether the CYP17 variant allele itself is causal or is in linkage disequilibrium with some other variant that has a causal relation with breast cancer.

\section{Competing interests}

The author(s) declare that they have no competing interests.

\section{Authors' contributions}

VTE performed the statistical analysis and drafted the manuscript. WGS carried out the molecular genetic studies and participated in the preparation of the manuscript. CCJ conceived the study, participated in its design and coordination, and contributed to the statistical analysis and the preparation of the manuscript. All authors read and approved the final manuscript.

\section{Acknowledgements}

We are grateful to the women who participated in this research project and the oncologists and gynecologists in the 40 clinics of the study regions for allowing us to contact their patients; and to Tanja Koehler for intensive technical assistance on genotyping and Ursula Eilber for competent data management. This work was supported by the Medical Faculty of the University of Ulm (P.589 and P.685), the Deutsche Krebshilfe e.V., and the Graduiertenkolleg 793 of the University of Heidelberg.

\section{References}

1. Feigelson HS, Henderson BE: Estrogens and breast cancer. Carcinogenesis 1996, 17:2279-2284.

2. Bennett IC, Gattas M, Teh BT: The genetic basis of breast cancer and its clinical implications. Aust N Z J Surg 1999, 69:95-105.

3. Johnson-Thompson MC, Guthrie J: Ongoing research to identify environmental risk factors in breast carcinoma. Cancer 2000, 88:1224-1229.

4. Picado-Leonard J, Miller WL: Cloning and sequence of the human gene for P450c17 (steroid 17 $\alpha$-hydroxylase/17,20 lyase): similarity with the gene for P450c21. DNA 1987, 6:439-448.

5. Dunning AM, Healey CS, Pharoah PDP, Teare MD, Ponder BAJ, Easton DF: A systematic review of genetic polymorphisms and breast cancer risk. Cancer Epidemiol Biomarkers Prev 1999, 8:843-854

6. Ye Z, Parry JM: The CYP17 MspA1 polymorphism and breast cancer risk: a meta-analysis. Mutagenesis 2002, 17:119-126.

7. Carey $A H$, Waterworth D, Patel K, White D, Little J, Novelli $P$, Franks S, Williamson R: Polycystic ovaries and premature male pattern baldness are associated with one allele of the steroid metabolism gene CYP17. Hum Mol Genet 1994, 3:1873-1876.

8. Feigelson HS, Coetzee GA, Kolonel LN, Ross RK, Henderson BE: A polymorphism in the CYP17 gene increases the risk of breast cancer. Cancer Res 1997, 57:1063-1065.

9. Kristensen VN, Haraldsen EL, Anderson KB, Lonning PE, Erikstein B, Karesen R, Gabrielsen OS, Borresen-Dale A-L: CYP17 and breast cancer risk: The polymorphism in the $5^{\prime}$ flanking area of the gene does not influence binding to Sp-1. Cancer Res 1999, 59:2825-2828.
10. Kadonaga JT, Carner KR, Masiarz FR, Tjian R: Isolation of cDNA encoding transcription factor $\mathrm{Sp} 1$ and functional analysis of the DNA binding domain. Cell 1987, 51:1079-1090.

11. Lin CJ, Martens JW, Miller WL: NF-1C, Sp1, and Sp3 are essential for transcription of the human gene for P450c17 (steroid 17 alpha-hydroxylase/17,20 lyase) in human adrenal NCIH295A cells. Mol Endocrinol 2001, 15:1277-1293.

12. Miyoshi $Y$, Ando A, Ooka M, Shiba E, Taguchi T, Tamaki $Y$, Noguchi S: Association of CYP17 genetic polymorphism with intra-tumoral estradiol concentrations but not with CYP17 messenger RNA levels in breast cancer tissue. Cancer Lett 2003, 195:81-86.

13. Haiman CA, Hankinson SE, Spiegelman D, Colditz GA, Willett WC, Speizer FE, Kelsey KT, Hunter DJ: The relationship between a polymorphism in CYP17 with plasma hormone levels and breast cancer. Cancer Res 1999, 59:1015-1020.

14. Feigelson HS, Shames LS, Pike MC, Coetzee GA, Stanczyk FZ, Henderson BE: Cytochrome P450c17 $\alpha$ gene (CYP17) polymorphism is associated with serum estrogen and progesterone concentrations. Cancer Res 1998, 58:585-587.

15. Hong C-C, Thompson HJ, Jiang C, Hammond GL, Tritchler D, Yaffe M, Boyd NF: Association between the T27C polymorphism in the cytochrome P450 c17 $\alpha$ (CYP17) gene and risk factors for breast cancer. Breast Cancer Res Treat 2004, 88:217-230.

16. Miyoshi Y, Iwao K, Ikeda N, Egawa C, Noguchi S: Genetic polymorphism in CYP17 and breast cancer risk in Japanese women. Eur J Cancer 2000, 36:2375-2379.

17. Hamajima N, Iwata $\mathrm{H}$, Obata $\mathrm{Y}$, Matsuo $\mathrm{K}$, Mizutani $\mathrm{M}$, Iwase $\mathrm{T}$, Miura S, Okuma K, Ohashi K, Tajima K: No association of the $\mathbf{5}^{\prime}$ promoter region polymorphism of CYP17 with breast cancer risk in Japan. Jpn J Cancer Res 2000, 91:880-885.

18. Huang C-S, Chern H-D, Chang K-J, Cheng C-W, Hsu S-M, Shen $\mathrm{C}-\mathrm{Y}$ : Breast cancer risk associated with genotype polymorhism of the estrogen-metabolizing genes CYP17, CYP1A1 and COMT: A multigenic study on cancer susceptibility. Cancer Res 1999, 59:4870-4875.

19. Bergman-Jungestrom $M$, Gentile $M$, Lundin $A-C$, Wingren $S$ : Association between CYP17 gege polymorphism and risk of breast cancer in young women. Int J Cancer 1999, 84:350-353.

20. Feigelson HS, Mckean-Cowdin R, Henderson BE: Concerning the CYP17 MspA1 polymorphism and breast cancer risk: a meta-analysis [letter to the editor]. Mutagenesis 2002, $17: 445-446$

21. Ambrosone $\mathrm{CB}$, Moysich $\mathrm{KB}$, Furberg $\mathrm{H}$, Freudenheim $\mathrm{JL}$, Bowman ED, Ahmed S, Graham S, Vena JE, Shields PG: CYP17 genetic polymorphism, breast cancer and breast cancer risk factors. Breast Cancer Res 2003, 5:R45-R51.

22. Mitrunen K, Jourenkova N, Kataja V, Eskelinen M, Kosma VM, Benhamou S, Vainio H, Uusitupa M, Hirvonen A: Steroid metabolism gene CYP17 polymorphism and the development of breast cancer. Cancer Epidemiol Biomarkers Prev 2000, 9:1343-1348.

23. Thompson PA, Ambrosone C: Molecular epidemiology of genetic polymorhisms in estrogen metabolizing enzymes in human breast cancer. I Natl Cancer Inst Monogr 2000, 27:125-134.

24. Wu AH, Seow A, Arakawa K, van den Berg D, Lee H-P, Yu MC: HSD17B1 and CYP17 polymorphism and breast cancer risk among Chinese women in Singapore. Int J Cancer 2003, 104:450-457

25. Chang-Claude J, Eby N, Kiechle M, Bastert G, Becher H: Breastfeeding and breast cancer risk by age 50 among women in Germany. Cancer Causes Control 2000, 11:687-695.

26. Feigelson HS, McKean-Cowdin R, Coetzee GA, Stam DO, Kolonel $L N$, Henderson BE: Building a multigenic model of breast cancer susceptibility: CYP17 and HSD17B1 are two important candidates. Cancer Res 2001, 61:785-789.

27. Spurdle AB, Hopper JL, Dite GS, Chen X, Cui J, McCredie MRE, Giles GG, Southey MC, Venter DJ, Easton DF, et al.: CYP17 promoter polymorphism and breast cancer in Australian women under age forty years. J Nat/ Cancer Inst 2000, 92:1674-1681.

28. Gudmundsdottir K, Thorlacius S, Jonasson JG, Sigfusson BF, Tryggvadottir L, Eyfjord JE: CYP17 promoter polymorphism and breast cancer risk in males and females in relation to BRCA2 status. Br J Cancer 2003, 88:933-936.

29. Helzlsouer KJ, Huang H-Y, Strickland PT, Hoffman S, Alberg AJ, Comstock GW, Bell DA: Association between CYP17 polymor- 
phisms and the development of breast cancer. Cancer Epidemiol Biomarkers Prev 1998, 7:945-949.

30. Weston A, Pan C-f, Bleiweiss IJ, Ksieski HB, Roy N, Maloney N, Wolff MS: CYP17 Genotype and breast cancer risk. Cancer Epidemiol Biomarkers Prev 1998, 7:941-944.

31. Dunning AM, Healey CS, Pharoah PD, Foster Na, Lipscombe JM, Easton DF, Day NE, Ponder BA: No association between a polymorphism in the steroid metabolism gene CYP17 and the risk of breast cancer. Br J Cancer 1998, 77:2045-2047.

32. García-Closas M, Herbstman J, Schiffman M, Glass A, Dorgan JF: Relationship between serum hormone concentrations, reproductive history, alcohol consumption and genetic polymorphisms in pre-menopausal women. Int J Cancer 2002, 102:172-178.

33. Michaud DS, Mansen JE, Spiegelman D, Barbieri RL, Sepkovic D, Bradlow HL, Hankinson SE: Reproducibility of plasma and urinary sex hormone levels in premenopausal women over a one-year period. Cancer Epidemiol Biomarkers Prev 1999, 8:1059-1064.

34. Jernström H, Vesprini D, Bradlow HL, Narod SA: Correspondence- Re: CYP17 promoter polymorphism and breast cancer in Ausralian women under age forty years. I Natl Cancer Inst 2001, 93:554.

35. Muti P, Bradlow HL, Micheli A, Krogh V, Freudenheim JL, Schunemann HJ, Stanulla M, Yang J, Sepkovic DW, Trevisan M, et al:: Estrogen metabolism and risk of breast cancer: a prospective study of the 2:16alpha-hydroxyestrone ratio in pre-menopausal and postmenopausal women. Epidemiology 2000, $11: 635-640$ 